\title{
Capsaicin induces cell cycle arrest and apoptosis in human KB cancer cells
}

\author{
Chia-Han Lin ${ }^{1 \dagger}$, Wei-Cheng Lư ${ }^{2 \dagger}$, Che-Wei Wang ${ }^{1}$, Ya-Chi Chan² and Mu-Kuan Chen ${ }^{1 *}$
}

\begin{abstract}
Background: Capsaicin, a pungent phytochemical in a variety of red peppers of the genus Capsicum, has shown an anti-proliferative effect on various human cancer cell lines. In contrast, capsaicin has also been considered to promote the growth of cancer cells. Thus, the effects of capsaicin on various cell types need to be explored. The anti-proliferative effects of capsaicin on human KB cancer cells are still unknown. Therefore, we examined the viability, cell cycle progression, and factors associated with apoptosis in KB cells treated with capsaicin.

Methods: The cell proliferation/viability and cytotoxicity of KB cells exposed to capsaicin were determined by a sulforhodamine B colorimetric assay and trypan blue exclusion. Apoptosis was detected by Hoechst staining and confirmed by western blot analysis of poly-(ADP-ribose) polymerase cleavage. Cell cycle distribution and changes of the mitochondrial membrane potential were analyzed by flow cytometry. Furthermore, the expression of caspase 3, 8 and 9 was evaluated by immunoblotting.
\end{abstract}

Results: We found that treatment of KB cells with capsaicin significantly reduced cell proliferation/viability and induced cell death in a dose-dependent manner compared with that in the untreated control. Cell cycle analysis indicated that exposure of KB cells to capsaicin resulted in cell cycle arrest at $\mathrm{G}_{2} / \mathrm{M}$ phase. Capsaicin-induced growth inhibition of KB cells appeared to be associated with induction of apoptosis. Moreover, capsaicin induced disruption of the mitochondrial membrane potential as well as activation of caspase 9, 3 and poly-(ADP-ribose) polymerase in KB cells.

Conclusions: Our data demonstrate that capsaicin modulates cell cycle progression and induces apoptosis in human KB cancer cells through mitochondrial membrane permeabilization and caspase activation. These observations suggest an anti-cancer activity of capsaicin.

Keywords: Capsaicin, KB cells, Cell cycle, Apoptosis, Mitochondria

\section{Background}

It is well known that natural phytochemicals widely present in certain daily consumed fruits and vegetables have inhibitory effects on various types of cancers at molecular and cellular levels [1,2]. Capsaicin, one of these naturally occurring phytochemicals, is the major pungent constituent of hot chili peppers of the genus Capsicum (family Solanaceae), which are extensively used as a food additive. It has been shown that capsaicin is involved in several physiological and pharmacological effects [3,4]. For example, several reports show that the use of capsaicin can

\footnotetext{
* Correspondence: 53780@cch.org.tw

${ }^{\dagger}$ Equal contributors

'Department of Otorhinolaryngology, Head and Neck Surgery, Changhua

Christian Hospital, 135 Nanhsiao St, Changhua, Taiwan

Full list of author information is available at the end of the article
}

relieve inflammation and pain associated with some diseases and cancer [5-7]. In addition, accumulating studies have shown that capsaicin has anti-proliferative effects on various human cancer cell lines including those derived from leukemia [8-10], multiple myeloma [11], cutaneous cell carcinoma [12], glioma [13,14], tongue cancer [15], nasopharyngeal carcinoma [16], esophageal carcinoma [17], gastric cancer [18], pancreatic cancer [19,20], hepatocarcinoma [21,22], colon carcinoma [23,24], non-small cell lung cancer [25], breast cancer [26,27], and prostate cancer $[28,29]$. The capacity of capsaicin to suppress the growth of these cancer cells is primarily mediated through induction of apoptosis. Additionally, the activities associated with capsaicin-induced anti-cancer effects include the arrest of cell cycle progression, regulation of transcription factor

\section{Ciomed Central}


expression, and suppression of growth signal transduction pathways.

The failure to control cancer cell death associated with the induction of apoptosis has been considered to be a critical cause of resistance against cancer therapy [30]. Apoptosis, a type of programmed cell death, is a physiological homeostatic mechanism. As a result of apoptosis, unwanted cells are eliminated in a well-organized sequential process. Apoptosis is characterized by various morphological and biochemical changes such as pyknosis, plasma membrane blebbing, mitochondrial membrane permeability, and the activation of caspase cascades [31]. It has been shown that the activation of apoptosis is mainly mediated through the extrinsic death receptor pathway and the intrinsic mitochondrial pathway, which involve a variety of caspase family members [30-32]. The extrinsic pathway is initiated by stimulation of death receptors that are members of the tumor necrosis factor receptor family. Activated death receptors induce formation of the death-inducing signaling complex (DISC) that subsequently promotes activation of caspase-8. The intrinsic pathway initiated by various intracellular signals, such as DNA damage, involves the mitochondrial response. Disruption of the mitochondrial membrane through the regulation of the Bcl-2 family members dissipates the mitochondrial transmembrane potential, resulting in the release of proapoptotic proteins, including cytochrome $\mathrm{c}$ and apoptosis-inducing factor, from the intermembrane space into the cytosol. Consequently, the apoptosome, a complex that stems from the interaction between cytochrome $\mathrm{c}$, apoptosis protease-activating factor 1 and ATP/dATP, activates caspase-9. Both extrinsic and intrinsic pathways induce the activation of caspase 3, 6 and 7 that subsequently cleave their substrates including poly-(ADP-ribose) polymerase (PARP), ultimately leading to apoptosis.

Despite our increasing understanding of the anticancer effects of capsaicin on the above-mentioned cancer cell lines, capsaicin has also been found to promote the growth of cancer cells [33,34]. The effects of capsaicin on various types of cancer need to be identified. The effect of capsaicin on human KB cancer cells remains unknown. Therefore, to gain insight into its effects, we determined whether exposure to capsaicin leads to cell cycle arrest and induction of apoptosis, and whether mitochondria and caspase members are involved in the programmed cell death. Here, we show that capsaicin induces arrest of the cell cycle at $G_{2} / M$ phase and causes apoptosis of KB cells. The capsaicin-induced apoptosis in KB cells is associated with mitochondrial membrane permeabilization and caspase activation. These results reveal that capsaicin may be useful for the prevention of cancer cell growth.

\section{Methods}

\section{Cell culture and chemicals}

Human KB cancer cells from the American Type Culture Collection (Manassas, VA, USA) were cultured in Dulbecco's modified Eagle's medium (GIBCO, Carlsbad, CA, USA) containing 10\% fetal bovine serum, $100 \mathrm{U} / \mathrm{ml}$ penicillin, and $100 \mu \mathrm{g} / \mathrm{ml}$ streptomycin (GIBCO) at $37^{\circ} \mathrm{C}$ in a humidified atmosphere with $5 \% \mathrm{CO}_{2}$. Capsaicin (Sigma, St. Louis, MO, USA) was dissolved in pure dimethyl sulfoxide (DMSO) (Sigma). All chemicals were of the highest grade available.

\section{Cell viability and cytotoxicity assays}

KB cells $\left(8 \times 10^{3}\right.$ cells/well $)$ were seeded in 96-well plates and cultured overnight. The cells were treated with various concentrations of capsaicin (1, 50, 100, 150, 200 and $250 \mu \mathrm{M}$ ) or DMSO (control group). After 24, 48 and $72 \mathrm{~h}$, cell proliferation and viability was determined by a sulforhodamine B (SRB) colorimetric assay [33]. Briefly, the cells were fixed in $10 \% \mathrm{w} / \mathrm{v}$ trichloroacetic acid (Sigma) and stained with $0.4 \%$ SRB (Sigma). The cells were then washed with tap water and 1\% acetic acid (Merck, Darmstadt, Germany). Protein-bound precipitates were dissolved in $10 \mathrm{mM}$ Tris buffer ( $\mathrm{pH}$ 10.5) (Merck), and the plate was read at a wavelength of $492 \mathrm{~nm}$ (Multiskan Spectrum Microplate Reader; Thermo Labsystems, Waltham, MA, USA) to determine the cell viability. Trypan blue exclusion was used to examine the numbers of viable and dead cells in each treatment. KB cells $\left(1 \times 10^{5}\right.$ cells/well $)$ cultured in 6 -well plates were treated with various concentrations of capsaicin (50,100, 150, 200 and $250 \mu \mathrm{M})$ or DMSO for 24,48 and $72 \mathrm{~h}$. After harvesting, cell suspensions were thoroughly mixed with equal volumes of a $0.4 \%$ trypan blue solution (GIBCO). Viable and dead cells were counted using a hemacytometer under an inverted phase contrast microscope (Nikon Eclipse Ti-U; Nikon Instruments, Kanagawa, Japan).

\section{Detection of apoptotic cells}

Cells cultured in 24-well plates were treated with capsaicin (150 and $250 \mu \mathrm{M}$ ) or DMSO for 24 and $48 \mathrm{~h}$. Following fixation in freshly prepared ice-cold 4\% paraformaldehyde (Sigma) and washing with PBS, $1 \mu \mathrm{g} / \mathrm{ml}$ Hoechst 33342 (Cell Signaling Biotechnology Inc., Beverly, MA, USA) was used to stain the cells. Images were acquired under an inverted fluorescence microscope equipped with a digital camera (Nikon Eclipse Ti-U; Nikon Instruments). The percentage of apoptotic cells were scored by counting at least 200 cells for each treatment. 


\section{Cell cycle analysis}

To detect the proportion of KB cells in different phases of the cell cycle, the DNA content in KB cells was detected by propidium iodide staining (Sigma) and flow cytometry. KB cells seeded in 6-well plates were incubated with capsaicin $(150$ and $250 \mu \mathrm{M})$ or DMSO for 24,48 and $72 \mathrm{~h}$, and then collected, washed with PBS, and fixed with 70\% ethanol at $-20^{\circ} \mathrm{C}$ overnight. After centrifugation, the cells were resuspended in PBS containing $4 \mu \mathrm{g} / \mathrm{ml}$ propidium iodide, $0.1 \mathrm{mg} / \mathrm{ml}$ RNase A (Amresco Inc., Solon, OH, USA) and 0.1\% Triton X-100 (Sigma), and then incubated at room temperature for $1 \mathrm{~h}$ in the dark. Finally, the cell cycle distribution of cells from each treatment was determined by flow cytometry (Beckman FC500; Beckman Instruments, Fullerton, CA, USA) with CXP software. The percentage of cells in different phases of the cell cycle was analyzed by MultiCycle DNA Content and Cell Cycle Analysis Software.

\section{Measurement of mitochondrial membrane potential $(\Delta \Psi \mathrm{m})$}

To elucidate the role mitochondria play in KB cell death after treatment with capsaicin, changes of the mitochondrial membrane potential were detected by flow cytometry using the fluorescent dye 3,3'-dihexyloxacarbocyanine iodide $\left(\mathrm{DiOC}_{6}\right)$ (Sigma). KB cells $\left(3 \times 10^{4}\right.$ cells/well) were seeded in 12-well plates. After incubation with various concentrations of capsaicin $(100,200$ and $250 \mu \mathrm{M})$ or DMSO for 24 and $48 \mathrm{~h}$, the cells were washed with PBS and resuspended in $10 \mathrm{nM} \mathrm{DiOC}_{6}$. After incubation at $37^{\circ} \mathrm{C}$ for $30 \mathrm{~min}$, the cells were immediately analyzed by flow cytometry.

\section{Immunoblotting}

After treatment of KB cells with capsaicin (50, 100, 150 and $250 \mu \mathrm{M}$ ) or DMSO for $24 \mathrm{~h}$, the cells were collected by trypsinization, washed twice with cold PBS, and then lysed with ice-cold lysis buffer consisting of $50 \mathrm{mM}$ Tris- $\mathrm{HCl}$ (pH 7.4), 0.1\% SDS, $150 \mathrm{mM} \mathrm{NaCl}, 1 \mathrm{mM}$ EDTA (Merck), 1\% Triton X-100 and a protease inhibitor cocktail (BioVision Research Products, Mountain View, CA, USA) of $0.001 \%(\mathrm{w} / \mathrm{v})$ aprotinin, $0.001 \%(\mathrm{w} / \mathrm{v})$ leupeptin, $0.00035 \%(\mathrm{w} / \mathrm{v})$ pepstain $\mathrm{A}$, and $0.085 \%(\mathrm{w} / \mathrm{v})$ PMSF. Cell lysates were kept on ice for $30 \mathrm{~min}$ after gentle vortexing, and then centrifuged at 11,752 $\mathrm{g}$ for $10 \mathrm{~min}$ at $4^{\circ} \mathrm{C}$. The supernatants were immediately analyzed by western blotting or stored at $-80^{\circ} \mathrm{C}$ until use. The protein concentration was measured by a BioRad assay according to the manufacturer's instructions. For western blot analysis, equal amounts of proteins $(20 \sim 50 \mu \mathrm{g})$ from each treatment were loaded on $12 \%$ SDS-PAGE gels. SDS-PAGE and electrophoretic transfer of proteins onto PVDF membranes (Millipore, Billerica, MA, USA) were performed with Hoefer and Bio-Rad apparati, respectively. PVDF membranes were soaked for $1 \mathrm{~h}$ in blocking buffer consisting of $5 \%$ non-fat milk powder or $5 \%$ bovine serum albumin (Sigma) in $1 \times$ PBS containing $0.5 \%$ Tween-20. Then, PVDF membranes were incubated with antibodies against caspase 8 (Santa Cruz Biotechnology Inc., Santa Cruz, CA, USA), caspase 9, caspase 3, PARP (Cell Signaling), and $\beta$-actin (Sigma) for $1 \mathrm{~h}$ or overnight. Membranes were then incubated with the appropriate secondary antibody conjugated to horseradish peroxidase for $1 \mathrm{~h}$. After the membranes were exposed to reagents for ECL immunodetection (Millipore), the labeled proteins were detected by autoradiographic film (Eastman Kodak Co., Rochester, NY, USA).

\section{Statistical analysis}

The Student's $t$-test was performed to determine the statistical significance of the difference between capsaicinand DMSO-treated groups. Results were represented as the mean $\pm \mathrm{SD}$ and considered significant at $\mathrm{P}<0.05$, unless stated otherwise.

\section{Results}

\section{Capsaicin suppresses growth and induces the death of human KB cancer cells}

To determine the effect of capsaicin on the proliferation of $\mathrm{KB}$ cells, a preliminary screening was performed to evaluate the proliferation and viability of $\mathrm{KB}$ cells using the SRB assay. As shown in Figure 1A, treatment with capsaicin $(1,50,100,150,200$ and $250 \mu \mathrm{M})$ for 24,48 and $72 \mathrm{~h}$ significantly inhibited the proliferation/viability of $\mathrm{KB}$ cells in a dose-dependent manner. In further experiments, we used trypan blue exclusion to evaluate the cytotoxicity of $\mathrm{KB}$ cells treated with capsaicin. As shown in Figure 1B, 24, 48 and $72 \mathrm{~h}$ exposure to varying concentrations of capsaicin (50, 100, 150, 200 and $250 \mu \mathrm{M})$ resulted in a significant dose-dependent reduction of viable cells, indicating that capsaicin exerts a cytotoxic effect on KB cells. Collectively, these data suggest that capsaicin treatment results in dose-dependent growth inhibition and induces cell death in KB cells.

\section{Capsaicin induces apoptosis in KB cells}

To elucidate whether the capsaicin-induced decrease of proliferation and viability of KB cells was associated with induction of apoptosis, the number of apoptotic cells was assessed by Hoechst staining. Based on the above results, we chose treatment with 150 and $250 \mu \mathrm{M}$ capsaicin for detection of apoptosis in KB cells. After KB cells were treated with capsaicin for 24 and $48 \mathrm{~h}$, the morphological changes of apoptotic cells, as described previously in [31], were visualized and recorded (Figure 2A). The percentage of apoptotic cells was scored and is summarized in Figure 2B. Similar to the above results, 

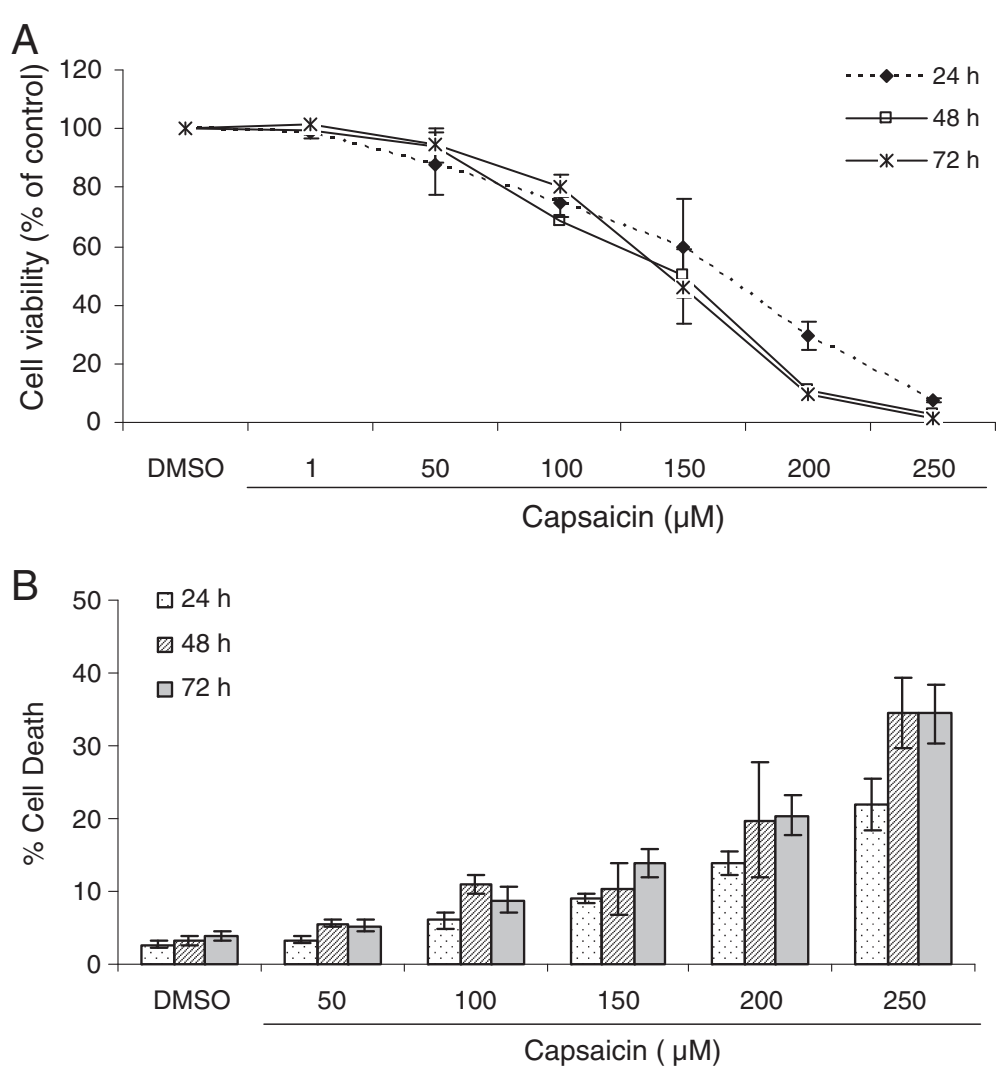

Figure 1 Capsaicin suppresses cell proliferation/viability and induces cell death in a dose-dependent manner. (A) The effect of capsaicin on the proliferation/viability of KB cells was determined by a SRB assay as described in the Methods. Data are representative of three independent experiments and are expressed as the means \pm SE of three replicates. (B) The cytotoxic effect of capsaicin on KB cells was determined by trypan blue exclusion as described in the Methods. Data are presented as the means \pm SE from three independent experiments.

the number of apoptotic cells appeared to show a dosedependent increase in response to capsaicin treatment. This observation indicates that the anti-proliferative effect of capsaicin on $\mathrm{KB}$ cells may be associated with induction of apoptosis.

\section{Capsaicin induces cell cycle arrest at G2/M phase in KB cells}

Cell proliferation is well correlated to the regulation of cell cycle progression. According to the preliminary assays, in which we observed a growth inhibition effect of capsaicin on KB cells (Figure 1), we chose 150 and $250 \mu \mathrm{M}$ capsaicin to investigate the possible effect of capsaicin on cell cycle progression. Cells harvested at various time points $(24,48$ and $72 \mathrm{~h}$ ) were analyzed by flow cytometry. As shown in Figure 3, there was no significant dose-dependent alteration of cell numbers in different cell cycle phases at $24 \mathrm{~h}$ compared with that in the control. This observation suggested that capsaicin did not modulate the cell cycle distribution within $24 \mathrm{~h}$. Capsaicin treatment at $250 \mu \mathrm{M}$ for 48 and $72 \mathrm{~h}$ induced an elevation of the number of cells in the $G_{2} / M$ phase of the cell cycle, while the number of cells in the $G_{1}$ phase decreased compared with that in the control. These data indicate that capsaicin treatment leads to the induction of $\mathrm{G}_{2} / \mathrm{M}$ arrest in $\mathrm{KB}$ cells.

\section{Capsaicin induces dissipation of the mitochondrial membrane potential $(\Delta \Psi \mathrm{m})$}

Mitochondria-initiated events are responsible for the intrinsic pathway of apoptosis. Various stress signals are capable of triggering mitochondrial membrane permeabilization that subsequently leads to the release of cytochrome $\mathrm{c}$ and other apoptogenic proteins from the mitochondria to the cytosol. Therefore, to determine whether a mitochondrial response was involved in the capsaicin-induced apoptotic pathway of $\mathrm{KB}$ cells, cells treated with capsaicin (100, 200 and $250 \mu \mathrm{M}$ ) for 24 and $48 \mathrm{~h}$ were labeled with $\mathrm{DiOC}_{6}$ to examine the changes of mitochondrial membrane potential $(\Delta \Psi \mathrm{m})$ by flow cytometry. As shown in Figure 4, peak shifts were observed in a dose-dependent manner in capsaicin-treated cells at 24 and $48 \mathrm{~h}$ compared with that in the control, thus confirming depolarization of the 


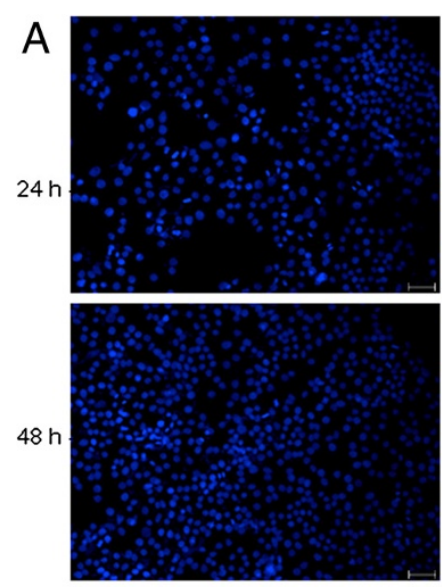

DMSO

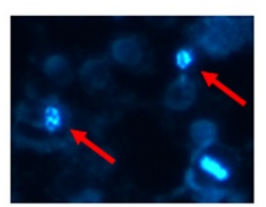

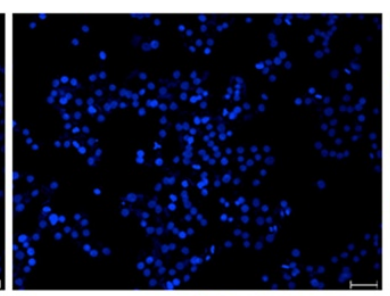
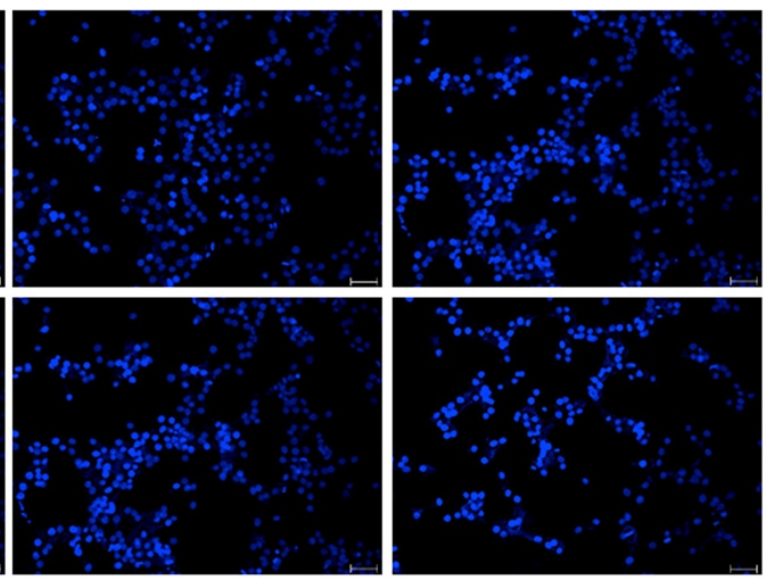

150

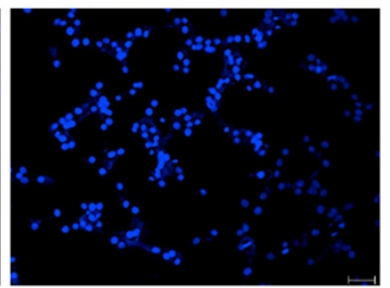

250

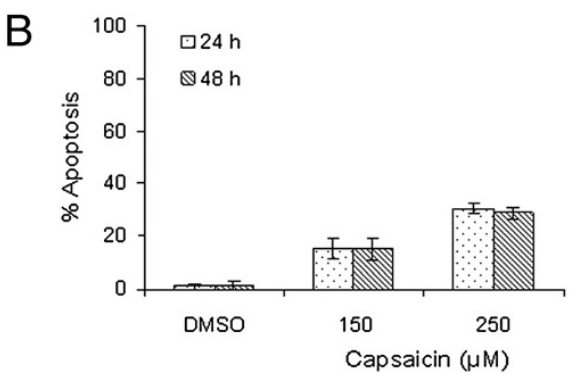

Figure 2 Capsaicin treatment results in apoptosis of KB cells. Apoptosis was assessed by Hoechst staining as described in the Methods. (A) The morphology of KB cells exposed to capsaicin was observed under a fluorescence microscope. Red arrows indicate apoptotic bodies. (B) The number of apoptotic cells was counted among at least 200 cells, and the percentage of apoptotic cells was charted. Data are representative of three independent experiments and are presented as the means \pm SE of three independent experiments. Scale bar, $100 \mu \mathrm{m}$.

mitochondrial membrane potential in $\mathrm{KB}$ cells treated with capsaicin.

\section{Capsaicin induces activation of caspases and PARP}

Caspase family members, including caspase 3,8 and 9, as well as downstream substrates such as PARP, are crucial mediators of the apoptotic process. The previous data indicated a significant decrease in the viability of $\mathrm{KB}$ cells at $24 \mathrm{~h}$ of exposure to capsaicin. We selected this time point to determine whether induction of apoptosis in KB cells treated with capsaicin was associated with the activation of caspases and PARP. As shown by western blotting in Figure 5, after KB cells were treated with capsaicin for $24 \mathrm{~h}(50,100,150$ and $250 \mu \mathrm{M})$, capsaicin induced the activation of caspase 9 in the apoptotic intrinsic pathway, resulting in a minor alteration of cleaved caspase 8 in the apoptotic extrinsic pathway compared with that in the control. Moreover, the expression of procaspase 3 decreased and PARP underwent cleavage, thereby confirming apoptosis. The expression of these proteins at the highest dose of capsaicin $(250 \mu \mathrm{M})$ decreased, except for PARP, which was probably because of extensive cell death or the terminal stage of apoptosis. These data suggest that capsaicin-induced apoptosis in KB cells is associated with caspase 3 and 9.

\section{Discussion}

Capsaicin is a naturally occurring plant phytochemical present in chili peppers. Whether it acts as a carcinogen, co-carcinogen, or anti-carcinogen is controversial [34,35]. Nonetheless, accumulating findings indicate that capsaicin possesses anti-cancer properties in various cancer cell lines [8-29]. The goal of this study was to explore the mechanism underlying capsaicin-induced cell death in human KB cancer cells. Here, we report that treatment of KB cells with capsaicin inhibits their proliferation/ viability, halts cell cycle progression, and induces apoptosis through mitochondrial membrane permeabilization and caspase activation.

In the preliminary study, we found that capsaicin treatment markedly reduced the proliferation and viability of KB cells (Figure 1), thus raising the possibility that capsaicin might be a potential chemopreventive or 


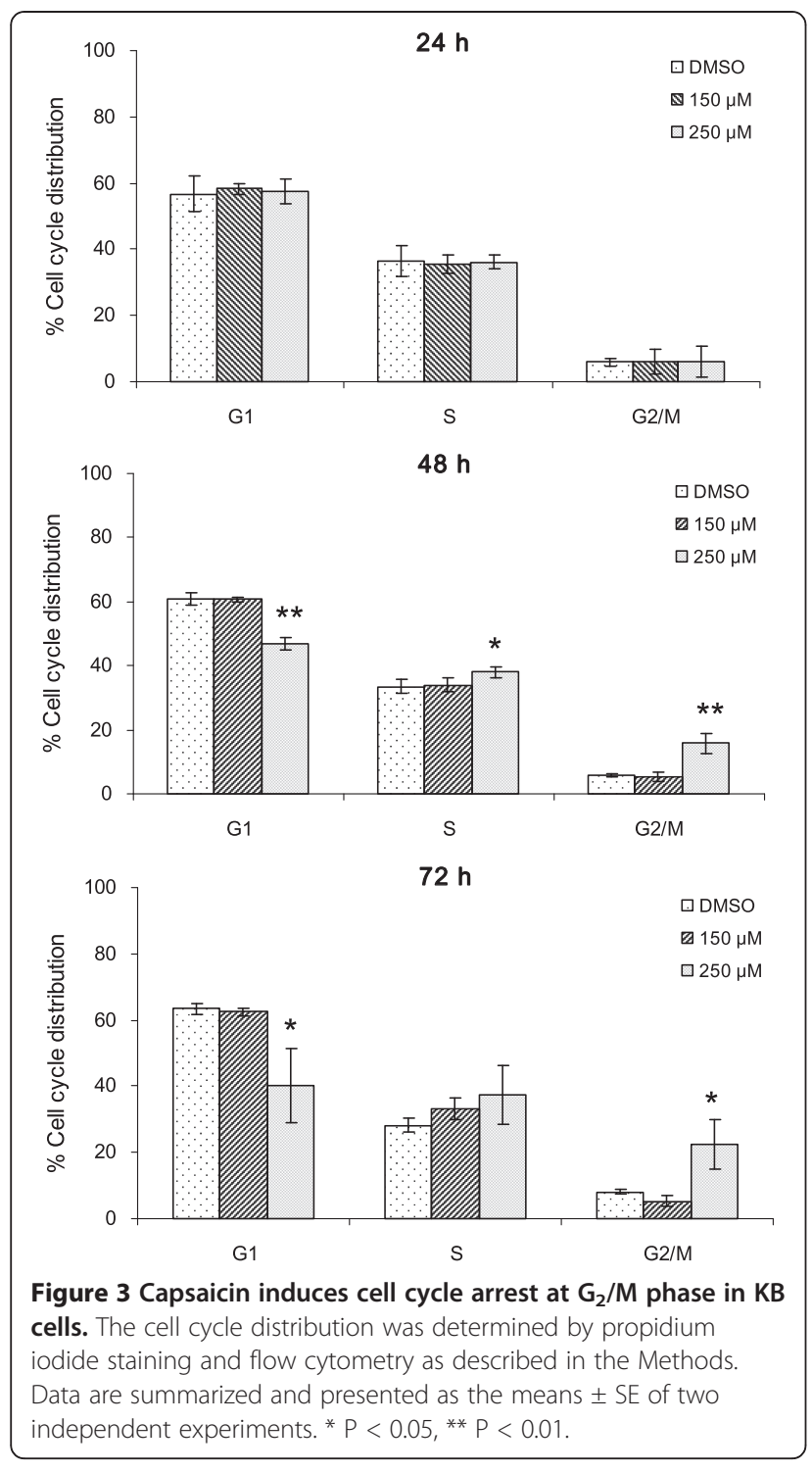

therapeutic agent. Several naturally occurring phytochemicals have been reported to suppress the growth of cancer cells through disruption of cell cycle progression $[1,2]$. Evading cell cycle arrest is the most frequently observed phenomenon in tumor development. The cell cycle includes a number of checkpoints that act as surveillance mechanisms. Upon cellular stress or DNA damage, these mechanisms induce cells to undergo either cell cycle arrest, activation of repair systems, or apoptotic induction. Checkpoints at $\mathrm{G}_{1} / \mathrm{S}$ and $\mathrm{G}_{2} / \mathrm{M}$ transitions are essential regulatory gates during cell cycle progression [36,37]. Numerous studies have shown a common feature in which exposure to capsaicin induces cell cycle arrest at the $G_{1}$ phase in a variety of human cancer cell lines [8-12,15-17,22,24,25,27,28]. Interestingly, we found that $G_{2} / M$ phase arrest of $K B$ cells was observed at the highest capsaicin concentration until $48 \mathrm{~h}$, and no earlier cell cycle arrest was found (Figure 3). This finding suggests that the mode of capsaicininduced cell cycle arrest depends on the cell type. Presently, the molecular mechanisms of capsaicin-induced cell cycle arrest in KB cells are unknown and require further investigation.

Apart from cell cycle arrest, induction of apoptosis is viewed as a mechanism through which a variety of naturally occurring phytochemicals inhibit tumor growth $[1,2]$. Recent studies have shown that capsaicin leads to induction of apoptosis in a variety of cancer cell lines [8-29]. The data obtained in our study demonstrated dose-dependent induction of apoptosis in KB cells treated with capsaicin. We found that capsaicin triggered the activation of apoptosis prior to $G_{2} / M$ phase arrest in $\mathrm{KB}$ cells (Figures 2, 3 and 5). As mentioned above, control of cell cycle progression is a strategy to halt tumor growth $[1,2,36,37]$. However, based on our data (Figures 1 and 3), it appears that inhibition of uncontrolled cell cycle progression plays a limited role in the inhibitory effect of capsaicin on KB cell growth. In fact, suppression of $\mathrm{KB}$ cell growth by capsaicin may be more correlated with induction of apoptosis.

Mitochondria-initiated responses are involved in regulation of the intrinsic apoptotic pathway [31,32]. Furthermore, the metabolic activities of mitochondria in cancer cells are distinct from those in normal cells, and are considered to be a biologically significant source of apoptotic failure that is closely associated with chemo- and radio-resistances in cancer therapy. Therefore, induced dysfunction of mitochondria is an attractive strategy for the control of cell proliferation. The loss of mitochondrial membrane stabilization is a key event to eliminate cancer cells [38,39]. Although exposure to capsaicin shows a slight change of mitochondrial membrane potential in MCF-7 breast cancer cells [26], multiple studies have revealed that capsaicin treatment leads to disruption of the mitochondrial membrane potential in various cancer cell lines $[9,10,12,14-17,19,20,22]$. These studies are consistent with our observation in which $\mathrm{KB}$ cells treated with capsaicin underwent loss of the mitochondrial membrane potential (Figure 4). Once the mitochondrial outer membrane is permeable, proapoptotic proteins such as cytochrome $\mathrm{c}$ are released into the cytosol from the intermembrane space, resulting in activation of caspase 9. Western blot analysis indicated the involvement of caspase 9 in capsaicin-induced apoptosis of KB cells (Figure 5). The other route of apoptosis, the extrinsic pathway, is initiated by the binding of ligands to death receptors. The transmembrane death signal induces formation of the DISC through adaptor proteins and 


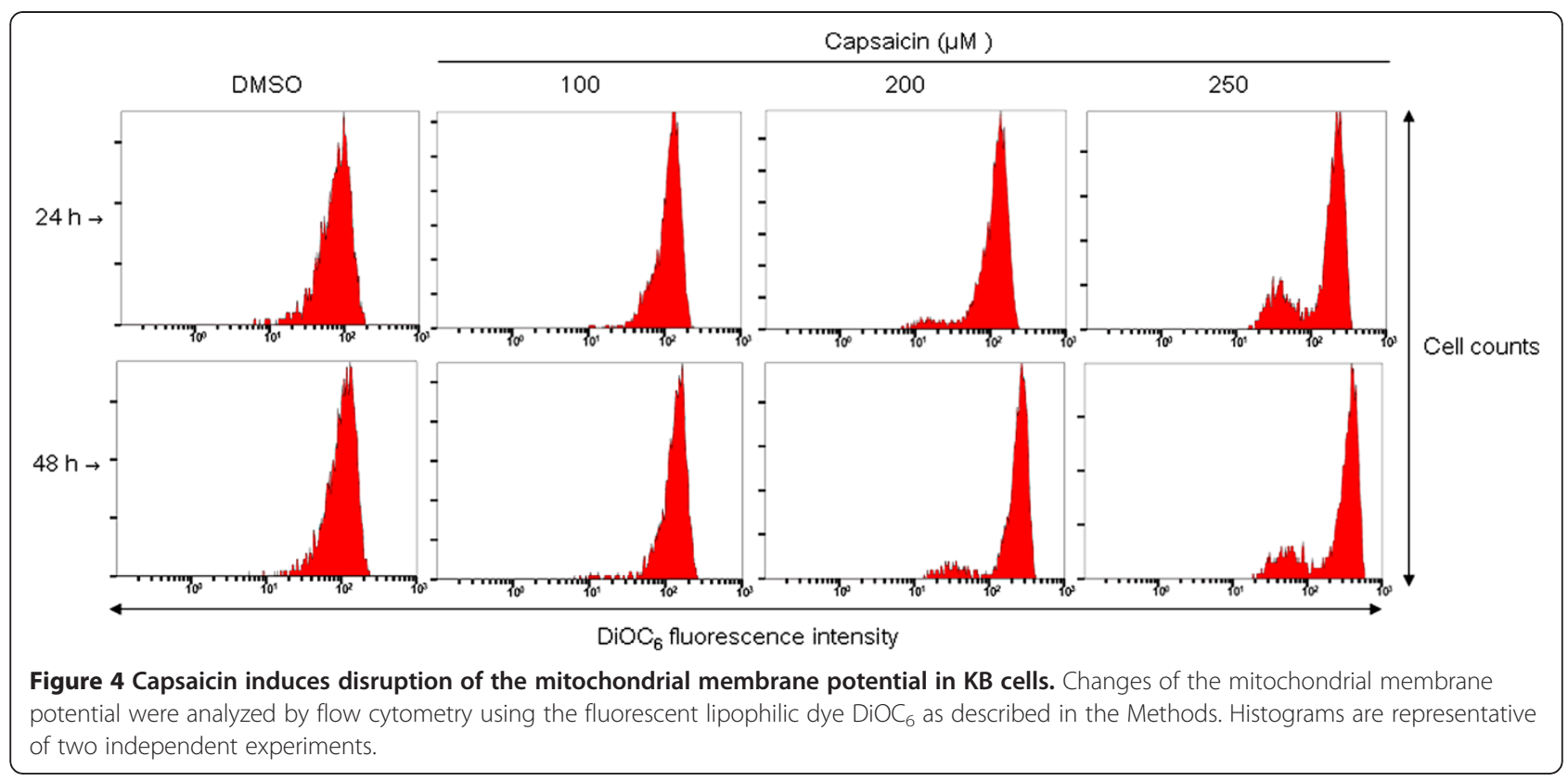

subsequently leads to activation of caspase 8. Our data showed that caspase 8 did not play a role in apoptosis of KB cells treated with capsaicin (Figure 5). Both intrinsic and extrinsic pathways converge on common factors including caspase 3. Upon activation of caspases 3, substrates such as PARP are cleaved, ultimately leading to apoptotic cell death [31,32]. Our results revealed that caspase 3 may be associated with capsaicin-induced apoptosis of KB cells (Figure 5). Collectively, mitochondria and caspase members are feasible targets of capsaicin for apoptosis of human cancer cells.

\section{Conclusions}

Our study indicates that exposure of human $\mathrm{KB}$ cancer cells to capsaicin reduces cell viability, induces cell cycle arrest at $G_{2} / M$ phase, and activates apoptosis that involves mitochondria and caspase members. However, capsaicininduced cell cycle arrest may not be effective for inhibition of $\mathrm{KB}$ cell growth. The apoptosis of KB cells treated with capsaicin is associated with the induction of caspase 3 and 9, as well as dissipation of the mitochondrial membrane potential. In summary, these findings suggest that capsaicin possesses an anti-cancer activity and may be a potential candidate as an anti-cancer agent.

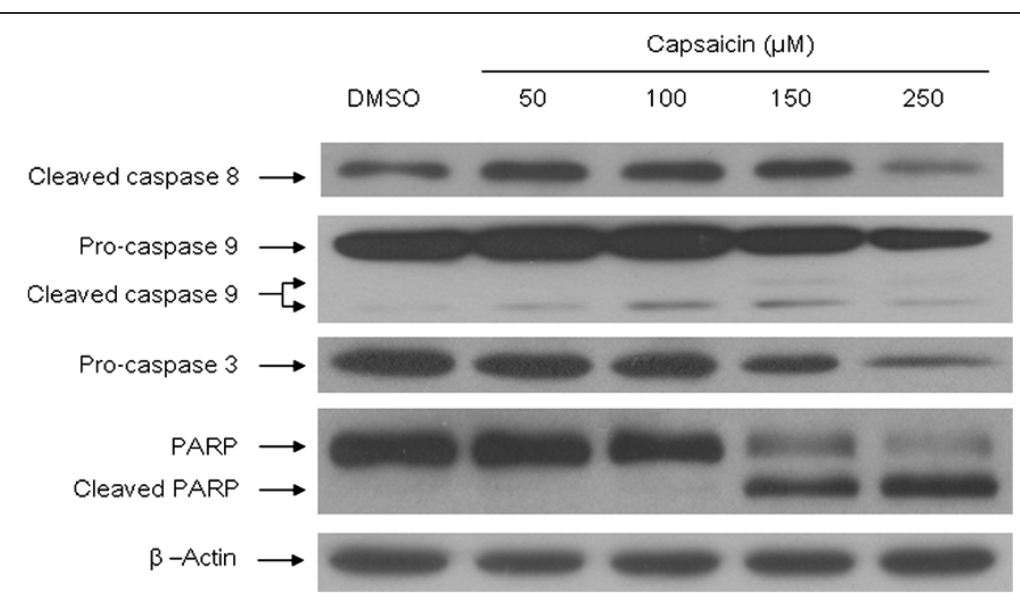

Figure 5 Apoptosis of KB cells is mediated through the activation of caspases. The effect of capsaicin on the activation of caspases and PARP was analyzed by immunoblotting as described in the Methods. Equal amounts of each sample were loaded on SDS-PAGE gels. The expression of caspase 3,8 and 9, PARP, and $\beta$-actin were detected using specific antibodies. Equal protein loading was confirmed by stripping and reprobing the blot to detect $\beta$-actin expression. The results are representative of at least three independent experiments. 


\section{Competing interests}

The authors have no competing interests.

\section{Authors' contributions}

CHL, WCL, and MKC conceived and designed the study. WCL and YCC performed the experiments. $\mathrm{CHL}, \mathrm{WCL}$, and $\mathrm{CWW}$ analyzed the data. $\mathrm{CHL}$ and WCL drafted the manuscript. CWW revised the manuscript. MKC provided comments and editorial review of the manuscript. All authors read and approved the final manuscript.

\section{Acknowledgements}

We thank Dr. Shun-Fa Yang and Dr. Shu-Fen Chiang for technical assistance. This work was financially supported by Changhua Christian Hospital.

\section{Author details}

'Department of Otorhinolaryngology, Head and Neck Surgery, Changhua Christian Hospital, 135 Nanhsiao St, Changhua, Taiwan. ${ }^{2}$ Cancer Research Center, Changhua Christian Hospital, Changhua, Taiwan.

Received: 25 September 2012 Accepted: 12 February 2013 Published: 25 February 2013

\section{References}

1. Chen C, Kong AN: Dietary cancer-chemopreventive compounds: from signaling and gene expression to pharmacological effects. Trends Pharmacol Sci 2005, 26:318-326.

2. Aggarwal BB, Takada Y, Oommen OV: From chemoprevention to chemotherapy: common targets and common goals. Expert Opin Investig Drugs 2004, 13:1327-1338.

3. Govindarajan VS, Sathyanarayana MN: Capsicum-production, technology, chemistry, and quality. Part V. Impact on physiology, pharmacology, nutrition, and metabolism; structure, pungency, pain, and desensitization sequences. Crit Rev Food Sci Nutr 1991, 29:435-474.

4. Szallasi A, Blumberg PM: Vanilloid (capsaicin) receptors and mechanisms. Pharmacol Rev 1999, 51:159-212.

5. Sancho R, Lucena C, Macho A, Calzado MA, Blanco-Molina M, Minassi A, Appendino G, Muñoz E: Immunosuppressive activity of capsaicinoids: capsiate derived from sweet peppers inhibits NF-kappaB activation and is a potent antiinflammatory compound in vivo. Eur J Immunol 2002, 32:1753-1763.

6. Berger A, Henderson M, Nadoolman W, Duffy V, Cooper D, Saberski L, Bartoshuk L: Oral capsaicin provides temporary relief for oral mucositis pain secondary to chemotherapy-radiation therapy. J Pain Symptom Manage 1995, 10:243-248.

7. Hayman M, Kam PCA: Capsaicin: a review of its pharmacology and clinical applications. Curr Anest Crit Care 2008, 19:338-343.

8. Zhang J, Nagasaki M, Tanaka Y, Morikawa S: Capsaicin inhibits growth of adult T-cell leukemia cells. Leuk Res 2003, 27:275-283.

9. Ito K, Nakazato T, Yamato K, Miyakawa Y, Yamada T, Hozumi N, Segawa K, Ikeda Y, Kizaki M: Induction of apoptosis in leukemic cells by homovanillic acid derivative, capsaicin, through oxidative stress: implication of phosphorylation of $\mathrm{p} 53$ at Ser-15 residue by reactive oxygen species. Cancer Res 2004, 64:1071-1078.

10. Tsou MF, Lu HF, Chen SC, Wu LT, Chen YS, Kuo HM, Lin SS, Chung JG: Involvement of $\mathrm{Bax}, \mathrm{BCl}-2, \mathrm{Ca}^{2+}$ and caspase-3 in capsaicin-induced apoptosis of human leukemia HL-60 cells. Anticancer Res 2006, 26:1965-1971.

11. Bhutani M, Pathak AK, Nair AS, Kunnumakkara AB, Guha S, Sethi G, Aggarwal BB: Capsaicin is a novel blocker of constitutive and interleukin- 6 -inducible STAT3 activation. Clin Cancer Res 2007, 13:3024-3032.

12. Hail N Jr, Lotan R: Examining the role of mitochondrial respiration in vanilloid-induced apoptosis. J Natl Cancer Inst 2002, 94:1281-1292.

13. Lee YS, Nam DH, Kim JA: Induction of apoptosis by capsaicin in A172 human glioblastoma cells. Cancer Lett 2000, 161:121-130.

14. Amantini C, Mosca M, Nabissi M, Lucciarini R, Caprodossi S, Arcella A, Giangaspero F, Santoni G: Capsaicin-induced apoptosis of glioma cells is mediated by TRPV1 vanilloid receptor and requires p38 MAPK activation. J Neurochem 2007, 102:977-990.

15. Ip SW, Lan SH, Huang AC, Yang JS, Chen YY, Huang HY, Lin ZP, Hsu YM, Yang MD, Chiu CF, Chung JG: Capsaicin induces apoptosis in SCC-4 human tongue cancer cells through mitochondria-dependent and independent pathways. Environ Toxicol 2012, 27:332-341.

16. Ip SW, Lan SH, Lu HF, Huang AC, Yang JS, Lin JP, Huang HY, Lien JC, Ho CC, Chiu CF, Wood W, Chung JG: Capsaicin mediates apoptosis in human nasopharyngeal carcinoma NPC-TW 039 cells through mitochondrial depolarization and endoplasmic reticulum stress. Hum Exp Toxicol 2012, 31:539-549.

17. Wu CC, Lin JP, Yang JS, Chou ST, Chen SC, Lin YT, Lin HL, Chung JG: Capsaicin induced cell cycle arrest and apoptosis in human esophagus epidermoid carcinoma CE 81 T/VGH cells through the elevation of intracellular reactive oxygen species and $\mathrm{Ca}^{2+}$ productions and caspase3 activation. Mutat Res 2006, 601:71-82.

18. Kim JD, Kim JM, Pyo JO, Kim SY, Kim BS, Yu R, Han IS: Capsaicin can alter the expression of tumor forming-related genes which might be followed by induction of apoptosis of a Korean stomach cancer cell line, SNU-1. Cancer Lett 1997, 120:235-241.

19. Zhang R, Humphreys I, Sahu RP, Shi Y, Srivastava SK: In vitro and in vivo induction of apoptosis by capsaicin in pancreatic cancer cells is mediated through ROS generation and mitochondrial death pathway. Apoptosis 2008, 13:1465-1478.

20. Pramanik KC, Boreddy SR, Srivastava SK: Role of mitochondrial electron transport chain complexes in capsaicin mediated oxidative stress leading to apoptosis in pancreatic cancer cells. PLoS One 2011, 6:e20151.

21. Jung MY, Kang HJ, Moon A: Capsaicin-induced apoptosis in SK-Hep-1 hepatocarcinoma cells involves $\mathrm{Bcl}-2$ downregulation and caspase-3 activation. Cancer Lett 2001, 165:139-145.

22. Huang SP, Chen JC, Wu CC, Chen CT, Tang NY, Ho YT, Lo C, Lin JP, Chung JG, Lin JG: Capsaicin-induced apoptosis in human hepatoma HepG2 cells. Anticancer Res 2009, 29:165-174.

23. Kim CS, Park WH, Park JY, Kang JH, Kim MO, Kawada T, Yoo H, Han IS, Yu R: Capsaicin, a spicy component of hot pepper, induces apoptosis by activation of the peroxisome proliferator-activated receptor gamma in HT-29 human colon cancer cells. J Med Food 2004, 7:267-273.

24. Lu HF, Chen YL, Yang JS, Yang YY, Liu JY, Hsu SC, Lai KC, Chung JG: Antitumor activity of capsaicin on human colon cancer cells in vitro and Colo 205 tumor xenografts in vivo. J Agric Food Chem 2010, 58:12999-13005.

25. Brown KC, Witte TR, Hardman WE, Luo H, Chen YC, Carpenter AB, Lau JK, Dasgupta P: Capsaicin displays anti-proliferative activity against human small cell lung cancer in cell culture and nude mice models via the E2F pathway. PLoS One 2010, 5:e10243.

26. Chou CC, Wu YC, Wang YF, Chou MJ, Kuo SJ, Chen DR: Capsaicin-induced apoptosis in human breast cancer MCF-7 cells through caspaseindependent pathway. Oncol Rep 2009, 21:665-671.

27. Thoennissen NH, O'Kelly J, Lu D, Iwanski GB, La DT, Abbassi S, Leiter A, Karlan B, Mehta R, Koeffler HP: Capsaicin causes cell-cycle arrest and apoptosis in ER-positive and -negative breast cancer cells by modulating the EGFR/HER-2 pathway. Oncogene 2010, 29:285-296.

28. Mori A, Lehmann S, O'Kelly J, Kumagai T, Desmond JC, Pervan M, McBride WH, Kizaki M, Koeffler HP: Capsaicin, a component of red peppers, inhibits the growth of androgen-independent, p53 mutant prostate cancer cells. Cancer Res 2006, 66:3222-3229.

29. Sánchez AM, Malagarie-Cazenave S, Olea N, Vara D, Chiloeches A, DíazLaviada I: Apoptosis induced by capsaicin in prostate PC-3 cells involves ceramide accumulation, neutral sphingomyelinase, and JNK activation. Apoptosis 2007, 12:2013-2024.

30. Fulda S, Debatin KM: Extrinsic versus intrinsic apoptosis pathways in anticancer chemotherapy. Oncogene 2006, 25:4798-4811.

31. Elmore S: Apoptosis: a review of programmed cell death. Toxicol Pathol 2007, 35:495-516.

32. Hengartner MO: The biochemistry of apoptosis. Nature 2000, 407:770-776.

33. Surh YJ, Lee SS: Capsaicin in hot chili pepper: carcinogen, co-carcinogen or anticarcinogen? Food Chem Toxicol 1996, 34:313-316.

34. Bode AM, Dong Z: The two faces of capsaicin. Cancer Res 2011, 71:2809-2814

35. Vichai V, Kirtikara K: Sulforhodamine B colorimetric assay for cytotoxicity screening. Nat Protoc 2006, 1:1112-1116.

36. Hartwell LH, Kastan MB: Cell cycle control and cancer. Science 1994, 266:1821-1828. 
37. Kastan MB, Bartek J: Cell-cycle checkpoints and cancer. Nature 2004, 432:316-323.

38. Gogvadze V, Orrenius S, Zhivotovsky B: Mitochondria in cancer cells: what is so special about them? Trends Cell Biol 2008, 18:165-173.

39. Costantini $P$, Jacotot $E$, Decaudin $D$, Kroemer G: Mitochondrion as a novel target of anticancer chemotherapy. J Natl Cancer Inst 2000, 92:1042-1053.

doi:10.1186/1472-6882-13-46

Cite this article as: Lin et al:: Capsaicin induces cell cycle arrest and apoptosis in human KB cancer cells. BMC Complementary and Alternative Medicine 2013 13:46.

\section{Submit your next manuscript to BioMed Central and take full advantage of:}

- Convenient online submission

- Thorough peer review

- No space constraints or color figure charges

- Immediate publication on acceptance

- Inclusion in PubMed, CAS, Scopus and Google Scholar

- Research which is freely available for redistribution 